AgNIESZKA ŻUR

Uniwersytet Ekonomiczny w Krakowie - Cracow University of Economics, Poland

\title{
Changing Entrepreneurship Learning Ecosystems: Massive Open Online Courses. Opportunities and Limitations
}

\begin{abstract}
Massive Open Online Courses (MOOCs) have brought innovation in terms of learning modes and new challenges at all levels of education, aiming to respond to the most pressing learning needs, generated by the new development policies and the rapid evolution of technology. This wave of change is affecting also entrepreneurial education. The goal of this study is to evaluate the opportunities and limitations of massive open online courses posed to higher education institutions. The study is based on desk research and analysis of existing MOOCs dedicated to entrepreneurship. The paper starts with introductory information about entrepreneurship and entrepreneurship education, as well as a short description of MOOC types. Next it presents an overview of existing top ranked online courses devoted to entrepreneurship education around the world. Finally, the paper identifies both opportunities and limitations of entrepreneurship MOOCs in regard to higher education institutions programs, as well as best practices identified as a result of the study.
\end{abstract}

Keywords: entrepreneurship courses; entrepreneurship education; MOOCs

Received: 28 October 2017

Accepted: 14 June 2018

\section{Suggested citation:}

Żur, A. (2018). Changing Entrepreneurship Learning Ecosystems: Massive Open Online Courses. Opportunities and Limitations.. Przedsiębiorczość - Edukacja [Entrepreneurship - Education], 14, 00-00. DOI: 10.24917/20833296.14.32

\section{Introduction}

Entrepreneurship education has gained importance given that it may influence the level of entrepreneurial activity in a given country (Kuratko, 2005), positively impact students' entrepreneurial intentions (Wach, 2015) or positively influence students' entrepreneurial traits (Dickson et al., 2008). Incorporating entrepreneurship learning modules in curricula is in line with the confirmation that teachers, academics, and professionals have moved away from the belief that entrepreneurs and managers are born, not made (Kuratko 2005); 
entrepreneurship can be taught and education can enhance entrepreneurial skills, competencies and attitudes (Peterman, Kennedy, 2003). As there is unanimity over the principles and values of entrepreneurship education as a means to enhance graduates' employability, approaches to execute it vary in many ways (Wach, 2013). Academics agree that entrepreneurship can be taught about (cognitive aspect), in or for (skills and attitude/behaviour). Therefore, curriculum design, teaching methodologies and didactics matter in this respect.

Recent years have brought a significant shift in entrepreneurship education due to the growth in scope and scale of massive open online courses (MOOCs). Some authors refer to MOOCs as disruptors of the educational order (Dodson, Kitburi, 2015). Increasingly more people are taking advantage of free and accessible courses on-line devoted to various aspects of entrepreneurship. New technology has made it possible to learn from successful entrepreneurs, the best professors, share experiences and exchange ideas between people. This new wave of entrepreneurship education can pose both threats and opportunities to higher education institutions with traditions and practice in entrepreneurship education.

It has been established in the past, that course design and curriculum delivery differences impact the entrepreneurship education quality and effectiveness (Mwasalwiba, 2010). Keeping that in mind, it is necessary to evaluate the potential contribution of existing entrepreneurship MOOCs and anticipate their value in future education programs. The aim of this paper is to bring together the existing research results on MOOCs in the context of entrepreneurship education and identify potential opportunities and limitations that MOOCs introduce for higher education institutions and entrepreneurship education.

The paper starts with a short summary of entrepreneurship education cannons and up-to-date advances. It then turns to massive open online courses as a special and distinctive kind of entrepreneurship education. Based on critical analysis of literature, the study outlines the specific unique features of MOOCs that distinguish them strongly from traditional education providers. Next, existing leading on-line MOOC platforms have been analysed to identify the types of courses dedicated to entrepreneurship in terms of content and design. The identified opportunities and limitations of MOOCs constitute the basis of a proposed framework for contemporary entrepreneurship education. The paper closes with conclusions and future research recommendations.

\section{Entrepreneurship and entrepreneurship education}

Entrepreneurship remains to receive immense academic (and non-academic) attention in the last decades (Stevenson, Lundstrüm, 2001). In its most narrow sense, entrepreneurship is defined as the process of new business creation (Timmons, 1985). However, in the last decades entrepreneurship and new venturing has been recognised and supported in numerous other fields of human activity, including social, academic and cultural. As an academic field of research entrepreneurship is conceptualised as the discovery and pursuit of opportunity (Shane, Venkataraman, 2000) and as such can be associated with numerous contexts and environments.

Entrepreneurship in its most broad and more popular sense is also conceptualised and perceived as a universal set of skills and attitudes that can be applied in undertakings in every context - new business, company project, social venture or international cultural exhibition (Di-Masi, 2010). Entrepreneurship skills and attitudes are essential at all stages 
of a professional career and add substantial value to all human activity. With this assumption, the European Union has launched numerous programs aimed at creating and reinforcing the entrepreneurial culture and entrepreneurship education is a fundamental element of its policy. European conceptual frameworks for entrepreneurship education encourage building an "entrepreneurial spirit, development of creativity, initiative and self-confidence". The European Union defines as one of the eight key competences for Lifelong Learning "Sense of initiative and entrepreneurship": "It is the ability to turn ideas into action. It involves creativity, innovation and risk-taking, as well as the ability to plan and manage projects in order to achieve objectives. The individual is aware of the context of his/her work and is able to seize opportunities that arise. It is the foundation for acquiring more specific skills and knowledge needed by those establishing or contributing to social or commercial activity. This should include awareness of ethical values and promote good governance" (European Parliament and Council, 2006).

And thus, in the last twenty years, we have witnessed an immense and dynamic growth of entrepreneurship teaching programs all over the world. Entrepreneurship education has become a standard practice at secondary and higher education institutions in countries around the world (Kuratko, 2005). This growth in volume and scope has been coupled by a sharp shift from educating about entrepreneurship to educating for entrepreneurship. Education about entrepreneurship is limited to knowledge transfer. Educating for entrepreneurship is driven by the goal to develop real-life entrepreneurial skills and behaviours. Some authors go as far as to say that the goal is to change thinking and behavioural patterns (Rae, 2005). Rae (2010: 595) defines entrepreneurial learning as "led by creativity, informality, curiosity, emotion and its application to personal and real-world problems and opportunities". Hence, contemporary education for entrepreneurship includes the promotion and training of personal skills related to entrepreneurship, such as creativity skills, problem-solving skills, communication skills and networking skills.

Comparative meta studies confirm that top entrepreneurship education programs place most emphasis on the following three aspects: (i) developing attitudes, values, intentions and behaviours, (i) improving interpersonal skills, and (iii) developing opportunity recognition skills (Mwasalwiba, 2010). The analysis of other publications reveals a very clear hierarchy of goals within entrepreneurship education, consistent with the above meta-analysis. Firstly, all existing conceptualisations include the dominating goal of developing an entrepreneurial drive, spirit and culture among students. In second place comes the goal of generating the ability to recognise and pursue opportunities in various areas, whether business, social or academic (Raposo, Paco, 2011). This is a significant shift, given that three decades ago the focus of entrepreneurship academic programs was only on developing the ability to create and operate new companies.

\section{Open Education and Massive Open Online Courses (M00Cs)}

The popularisation of entrepreneurship education has accelerated in the last two decades in great part thanks to the new opportunities brought by information technologies. Online courses facilitate the development of entrepreneurial skills by individuals on their own by means of electronic devices. Today, thanks to technology, entrepreneurship education is not only easy to access, but it has become more abundant and diversified than ever. Contemporary authors and educators (Pittaway, Cope, 2007; Rigg, O’Dwyer, 2012) 
articulate that Massive Open Online Courses (MOOCs) open a new era in entrepreneurship education. The precursors of MOOCs include all prior forms of distance learning, starting with correspondence courses and ending with e-learning courses. The philosophy of open education emerged in the 1970s and was based on ideas of holistic education and the opportunity to experience education regardless of the location, prior education and material status for everyone (Dodson, Kitburi, 2015). Yet, it is the MOOC format which brought out these assumptions in their full form.

MOOCs can be defined as a technology-based learning format that encourages open education (Dodson, Kitburi, 2015). Open refers to freedom of geographical distance and not bounded by the classroom; they are entirely online and therefore able to serve vary large number of learners. MOOCs are also usually open in the sense that they do not require formal prerequisites of prior education allowing learners of all backgrounds, including those without formal education, to benefit and learn free of charge. There are two broad categories of MOOCs. The design of xMOOCs relies on teaching and learning methods typical for higher education: there is a clear distinction between the instructor and the learner. MOOCs also have their formal syllabus and study plan. Assessment is usually carried out with quizzes and can be self-paced, available to all learners at different times. Therefore most MOOCs align with the instructivist pedagogy. cMOOCs on the other hand, are based on social constructivist pedagogy. The $c$ in the name stands for connectivist, as these courses employ collaborative tools and emphasize knowledge sharing and social interaction. Students work in groups, form social networks and social interactions are the key to the learning experience. cMOOCs are therefore set in time and all learners need to start the course at the same time. Therefore it has been assessed that xMOOCs focus on knowledge dissemination and duplication, whereas cMOOCs focus on knowledge creation and sharing. The two models rely on contrasting pedagogies and serve different learning needs and preferences. A vast number of existing MOOCs adapt a mixed approach, incorporating elements of both models and these are referred to as hybrid MOOCs.

From the very beginning in 2010s MOOCs have been developed by or in cooperation with leading universities creating high quality content. The first MOOCs were xMOOCs designated to disseminate university knowledge and make it accessible for the many, and not only the exclusive few who are able to afford university education. This stream of courses still remain most popular as they are tried, tested and rated by thousands of previous learners.

The existing on-line learning materials devoted to entrepreneurship vary greatly in their focus on subject area, audience, content, other features. Various entrepreneurship online courses have already been offered in the 2000s (e.g. MIT OpenCourseWare "Entrepreneurial Marketing" in 2002) and one of the first European MOOCs was devoted to idea creation and creativity (ThinkTank - Ideal City of the 21st Century by Leuphana Digital School in January 2013). Over time we have observed an exponential growth rate of entrepreneurship MOOCs in the global educational landscape. According to Class Central, the largest search engine for MOOCs (https://www.class-central.com), the number of MOOCs relating to business and management in 2015 doubled in comparison to 2014 (from 339 courses to 705 courses) and is still growing very fast. 


\section{Methodology}

The goal of this study is to identify opportunities and limitations that entrepreneurship MOOCs present to traditional academic entrepreneurship education. The conducted empirical research is based on a detail analysis of leading MOOC platforms: Coursera, edX, Udacity, Openlearning, Openlearn, Futurelearn, iversity, Alison and Canvas Network. Each of these platforms offer a variety of MOOCs devoted to entrepreneurship, entrepreneurial skills and business start-ups. The courses with highest learners' ratings have been analysed in terms of content and design.

The courses were identified by applying search words indicated by Class Central as the search words for entrepreneurship courses. These were alphabetically: entrepreneur, entrepreneurship, innovation, scaling, social entrepreneurship, start-ups, venture capital, ventures. Only English language courses have been included in the analysis and only those with high rating delivered by the learners. 53 courses have been included for analysis.

In the second step, the descriptions and syllabi of the on-line courses have been analysed and compared using a dedicated excel sheet, which served as results protocol. The goal was to identify the potential opportunities and limitations these leading courses present for traditional academic courses. The effects the performed analysis have been confronted with the existing literature to provide a holistic and in-depth list of potential opportunities and benefits, as well as risks and limitations.

\section{Findings and Analysis}

The joint analysis of the leading MOOC platforms revealed an unequal distribution of entrepreneurship themes in existing online courses. Some of these are plentiful while others very scarce in the existing online offer. Three groups of courses have been identified based on the topic and content: (i) start-ups and new venture creation, (ii) growth of general entrepreneurial skills, and (iii) firm-level entrepreneurship courses. Highly rated courses have been provided as examples in brackets.

The study revealed that the existing offer of online entrepreneurship courses is greatly dominated by courses on start-ups. Within this vast group of courses, most existing MOOCs concentrate on universal start-up skills and processes necessary to successfully launch a business. The most popular in this regard is "Starting a business" developed by the University of Leeds and hosted by Futurelearn Entrepreneurship. Several thematic subgroups of courses have been identified relating to start-ups in a specific contexts. Among these a number of courses focus on: tech and high-tech entrepreneurship ("Creating and Developing a Tech Startup" developed by Ecole Polytechnique in Paris and hosted by Canvas Network), international new ventures and born-globals ("Global Entrepreneurship" developed by Taylor University and hosted by Openlearn) and social entrepreneurship (“Social Entrepreneurship" developed by Copehagen Business School and hosted by Coursera). This broad category of entrepreneurship MOOCs is by far the most numerous.

The second group of courses in regard to their quantity, are those dedicated to growing general entrepreneurial skills. These are addressed to the general public and focus on developing creativity skills, opportunity recognition skills, time management skills, organisational skills and general management skills ("Essentials of Entrepreneurship: 
Thinking \& Action" developed by University of California and hosted by Coursera). These skills serve to reinforce entrepreneurial postures, enhance career development or to increase the employability of the unemployed.

Courses relating to firm-level entrepreneurship, remain to date largely unaddressed by online education. Courses dedicated to enhancing general entrepreneurial skills fall into this category to some extent, although there are very few courses dedicated to creating an entrepreneurship-friendly environment or an entrepreneurial orientation of companies, nor courses dedicated to facilitating entrepreneurial behaviour of companies in the form of radical innovation, spin-offs or high-risk investments in our research ("Corporate Entrepreneurship: Innovating within corporations" developed by the University of Maryland and hosted by Coursera).

The analysis revealed rich thematic content of top courses included in the sample. The design is quite equally distributed between xMOOCs, cMOOC and hybrid MOOCs. The existing entrepreneurship courses present numerous opportunities and potential benefits for the current state of university entrepreneurship education. Higher education institutions can be both users and producers of MOOCs. The high quality of the content of top entrepreneurship courses encourage their incorporation in university educational programs. This can be done in many ways and the flexibility is high. MOOCs can be incorporated as additional modules of various entrepreneurship courses and thus play a complimentary role. MOOCs can be the basis of blended learning courses. MOOCs can be also included in the set of elective courses at universities. Another role MOOCs can play is filling in knowledge gaps for students in need of repetition or a degree of prior knowledge required for a university course. MOOCs can also play an important role in distance learning.

The first argument for some level of incorporation of MOOCs in on-site educational programs is quality. There is very little risk of inadequate quality: the value of top entrepreneurship courses have been proven by very large numbers of learners throughout several years. Highly rated courses have been developed by top professors and teams of experts from leading world institutions. Their value added to standard education is very promising. Second argument refers to rich and varied content. The study revealed that most of the existing entrepreneurship MOOCs include interviews or talks not only by professors, but also by top world entrepreneurs. It has been assessed in the past that inspiration plays a key role in entrepreneurial education (Żur, 2014b). MOOCs offer the possibility to learn and be inspired by different entrepreneurs from around the world. This international perspective is valuable as it strengthens the understanding of the universality of entrepreneurship. The content of the analysed MOOCs was diverse in terms of geographical and cultural context. This presents a valuable opportunity to develop intercultural awareness while studying using MOOCs, identified by prior studies (Whitaker, New, Ireland 2016). Entrepreneurship education plays an important role in delivering awareness and responsibility for world issues (Żur, 2014b)

Third, the incorporation of MOOCs in university entrepreneurship education enables the redefinition of the traditional role of on-site instructor. Instead of focusing on knowledge dissemination, the academic teacher can fill the role of a moderator and facilitator of the educational process providing assistance and additional insights for student MOOC participants (Bogdan 2017). This provides a unique opportunity for entrepreneurship students which they would not have otherwise. In-class discussions and in-class projects can be based on the content of the MOOC minimizing the risk of passive education. 
Incorporating MOOCs in educational programs can enhance the learning experience of students.

The fact that MOOCs are offered free of charge presents also a cost benefit; MOOCs can reduce the costs of education as they do not require the purchase of a license. There are however existing limitations and challenges that need to be acknowledged. The most important one is accreditation of MOOCs. The analysed MOOCs do not include guidelines how to translate the completion of a MOOC to university credits such as ECTS points. This would need to be addressed with internal university regulations and procedures. Some universities already have committees for accreditation of informal educational outcomes. The accreditation of content validity and alignment with university programs is obtained through a thorough analysis of the MOOC content, design and quality performed by experts in the subject matter. Similarly, the credentials that count toward university diplomas can also be assessed by a dedicated committee, whose members are experts on MOOCs and have a long experience in teaching entrepreneurship courses at university level.

Another limitation in the case of some universities is internal regulations requiring university courses to include only original material in the education process. These regulations can be altered or redefined, as higher education institutions have a large degree of autonomy in shaping their educational policy and are able to introduce formal regulations admitting selected MOOCs in their university courses.

The third, and maybe most difficult to overcome in short term, challenge refers to the mindset of university educators. MOOCs can challenge the old ways of delivering education and can pose a threat to traditional courses in the mind of some academic teachers, as identified by Blackmon (2016). Students of generation Y and Z might regard MOOCs as more attractive, up-to-date, flexible and simply more interesting, especially in the digital age. Incorporating MOOCs in university program will require educators to adapt to their new roles.

The last identified limitation refers to privacy rights of MOOC users. Prior works have raised the concern that data of students enrolled in MOOCs is accessible for the MOOC providers and the University has no longer guard over student data in the narrow aspect of the MOOC (Jones, Regner, 2016). To enrol, students must provide their personal information. A recent study revealed an inconsistency among MOOC platforms regarding the handling of personal data. This legal aspect poses a risk and a potential threat of legal uncertainty.

The analysis of top entrepreneurship MOOCs revealed an important benefit which MOOC developers can take advantage of. A high quality MOOC serves as a channel of branding and marketing for universities. Studies found that students are beginning to use MOOCs as a reference point when choosing their future university (Whitaker, New, Ireland, 2016). This is especially relevant for master programs. A MOOC can educate and inform a global student audience about the learning opportunities at selected universities. A high quality MOOC will encourage prospective students, who have completed the MOOC with great satisfaction, to research further the institution and its educational programs. This aspect can encourage other universities to become developers and producers of MOOCs.

Finally, the analysis of top entrepreneurship MOOCs has led to the identification of best practices which these top ranked courses have in common. Several good practices 
which impact the quality of the courses have been identified. These are:

- clear description of the course, its modules, learning goals and outcomes,

- rich academic thematic content,

- testimonies of successful entrepreneurs,

- learning from failure stories,

- incentives for students (idea pitch, student competition, mentoring),

- high quality video/audio content,

- e-books and high quality materials to download,

- possibility to work in groups not only individually,

- interactions with instructor,

- interactions with other participants to exchange ideas and experience using available online tools,

- multiple and diverse methods of evaluation,

- continuous feedback and tracking progress tools,

- certificate or statement of participation,

- possibility of submitting user feedback to the course.

With the vast amount of offerings and new MOOCs emerging at a constant rate, it is difficult to choose and select a course catering specific educational needs. Different online repositories facilitate a search for finding the current offerings, in an appropriate timeframe (or self-paced), language, didactical approach, workload, subtopic, quality, certification options. The study revealed that the wide choice entrepreneurship MOOCs presents an opportunity for standard university courses. Thus the growing numbers of entrepreneurship MOOCs mark an important trend not only in open education, but also in university entrepreneurship education. It is very unlikely that MOOCs with become an integral part of university education. Most authors agree that "MOOCS are just one spice among many online-education spices" (Voss, 2013: 1), but one that can spice up the educational process significantly.

\section{Conclusions}

The objective of this study was to evaluate the opportunities and challenges posed by existing entrepreneurship MOOCs for traditional university entrepreneurship programs. The study was based on an analysis of 53 leading entrepreneurship MOOCs provided by 8 international MOOC platforms. The study has established that entrepreneurship courses themselves are a strong current trend in the global MOOC movement. The analysis has revealed three streams of entrepreneurship MOOC education and a number of significant benefits of incorporating MOOCs in university entrepreneurship programs. The main challenge identified is the problem of formal accreditation of MOOCs by universities. Lastly, the analysis revealed common traits of high-quality entrepreneurship MOOCs.

The contribution of this study lies in identifying an important disruptive element of global entrepreneurship education along with opportunities presented by the quickly growing body of MOOCs bring to university entrepreneurship education.

This study is published as part of a project no. 2015-2929/001-001 "Knowledge Alliance to enable a European-wide exploitation of the potential of MOOCs for the world of business" financed by the European Union. 
References

Analytical Report Entrepreneurship in the EU and Beyond. European Commission. (2010). Flash Eurobarometer, 283.

Blackmon, S.J. (2016). Through the MOOCing Glass: Professors' Perspectives on the Future of MOOCs in Higher Education. New Directions for Institutional Research, 167, 87-101.

Bogdan, R. (2017). Intergrating MOOCs in embedded systems of blended courses. Broad Research in Artificial Intelligence and Neoroscience, 8(3), 101-107.

Di-Masi, P. 2010, 'Defining Entrepreneurship: What is Entrepreneurship?': http://www.gdrc.org/icm/ micro/define-micro.html

Dodson, M.N., Kitburi, K., Berge, Z.L. (2015). Possibilities for MOOCs in corporate training and development. Performance Improvement, 54(10), 14-21.

European Parliament and Council 2006, Recommendation of the European Parliament and of the Council of 18 December 2006 on key competences for lifelong learning. OJ L 394, 10-18.

Jones, M.L., Regner, L. (2016). Users or students? Privacy in university MOOCS. Science and engineering ethics, 22(5), 1473-1496.

Kuratko, D.F. 2005, 'The emergence of entrepreneurship education: development, trends and challenges'. Entrepreneurship Theory and Practice, 29(5), 577-598.

Mwasalwiba, E.S. (2010). 'Entrepreneurship Education: a review of its objectives, teaching methods and impact indicators', Education and Training, 52(1), 20-47.

Peterman, N.E., Kennedy, J. (2003). Enterprise education: Influencing students' perceptions of entrepreneurship. Entrepreneurship theory and practice, 28(2), 129-144.

Pittaway, L., Cope, J. (2007). 'Entrepreneurship education: a systematic review of the evidence'. International Small Business Journal, 25(5), 479-510.

Rae, D. (2005). 'Entrepreneurial learning: a narrative-based conceptual model', Journal of Small Business \& Enterprise Development, 12(3), 323-335.

Rae, D. (2010). 'Universities and enterprise education: responding to the challenges of the new era', Journal of Small Business and Enterprise Development, 17(4), 591-606.

Raposo, M., Paco, A. (2011). 'Entrepreneurship education: relationship between education and entrepreneurial activity'. Psicothema, 23(3), 453-457.

Rigg, C., O’Dwyer, B. (2012). Becoming an entrepreneur: researching the role of mentors in identity construction. Education and Training, 54(4), 319-329.

Shane, S., Venkataraman, S. (2000). The promise of entrepreneurship as a field of research, Academy of Management Review, 25(1), 217-226.

Stevenson, L., Lundstrüm, A. (2001). Patterns and Trends in Entrepreneurship/SME Policy and Practice in ten Economies, Entrepreneurship Policy for the Future Series, 3, 11-32.

Timmons J.A. (1985). New Venture Creation, Homewood Illinois.

Voss, B. (2013). Massive Open Online Courses: A Primer for University and College Board Members, Association of Governing Boards.

Wach, K. (2015). Środowisko biznesu rodzinnego jako stymulanta intencji przedsiębiorczych młodzieży akademickiej. Przedsiębiorczość i Zarządzanie, 16(7/3), 25-40.

Wach, K. (2013). Edukacja na rzecz przedsiębiorczości wobec współczesnych wyzwań cywilizacyjno-gospodarczych. Przedsiębiorczość- Edukacja, 9, 246-257.

Whitaker, J., New, J.R., Ireland, R.D. (2016). MOOCs and the Online Delivery of Business Education What's new? What's not? What now? Academy of Management Learning \& Education, 15(2), 345365.

Żur, A. (2014a). Entrepreneurial education for social responsibility, Przedsiebiorczość - Edukacja, 10, 346-353.

Żur, A. (2014b). Exploring the Role of Inspiration in Entrepreneurship Education. Horyzonty Wychowania, 13(26), 179-194. 
Agnieszka Żur, $\mathrm{PhD}$ in management (corporate entrepreneurship). Graduate and later employee of Cracow University of Economics. Author of publications on corporate entrepreneurship, social entrepreneurship and higher education teaching and learning. Current research areas: social entrepreneurship, teaching methodology, socially engaged teaching and learning, tutoring and mentoring. Extensive experience in teaching entrepreneurship, management and research methodology (BA, MA, MBA, PhD students). Author of course programmes based on flipped classroom and social constructivist theory. Certified trainer and academic tutor.

\section{Address:}

Cracow University of Economics

Rakowicka 27

31-510 Kraków, Poland

e-mail: zura@uek.krakow.pl 